\title{
A HUMAN CASE OF SWINE INFLUENZA VIRUS INFECTION IN EUROPE - IMPLICATIONS FOR HUMAN HEALTH AND RESEARCH
}

\author{
K Van Reeth (Kristien.VanReeth@UGent.be) ${ }^{1}$, A Nicoll² \\ 1. Laboratory of Virology, Faculty of Veterinary Medicine, Ghent University, Belgium \\ 2. European Centre for Disease Prevention and Control, Stockholm, Sweden
}

Swine are susceptible to the same influenza A virus subtypes as humans - H1N1, H3N2 and H1N2 - and the histories of influenza in pigs and people are closely linked [1]. Many swine influenza viruses are a result of reassortment and their genes are composed of human and avian and/or swine virus genes. Indeed, it is known that both human and avian influenza viruses occasionally transmit to pigs, and that pigs can serve as "mixing vessels" for these viruses, meaning that viruses can exchange genetic material and lead to the production of a new "hybrid" virus [2]. This has led to the thinking that perhaps pandemic viruses could emerge following reassortment in pigs. However, since nobody has observed the start of a pandemic, there remains no direct evidence to make this more than a theory.

Influenza is one of the major causes of acute respiratory disease in pigs, but subclinical infections are also common. Unlike the non-zoonotic swine fevers it is not a disease that comes under the European Union's harmonised Animal Disease Notification System and there are no routine European surveillance data. The symptoms and pathogenesis of influenza in pigs show remarkable similarities with those of seasonal influenza in humans, but the epidemiology is different. Part of this is due to the structure of the swine industry and the extremely rapid turnover of the swine population, with the constant introduction of immunologically naïve animals into swine herds. In swine-dense regions in particular, most pigs show serological evidence of having been infected with influenza by the end of the six-month-long fattening period, and many of them have undergone simultaneous or consecutive infections with two or even three swine influenza subtypes [3]. Unlike human viruses in temperate climates, swine influenza viruses circulate at comparable levels year round. Also, the viruses in Europe differ significantly in their antigenic and genetic make-up from those circulating in North America, even though they consist of the same $\mathrm{H}$ and $\mathrm{N}$ subtypes, and hence findings in the United States should not necessarily be extrapolated to Europe.

Humans in contact with pigs occasionally become infected by swine influenza viruses [4]. This issue of Eurosurveillance reports on a case of swine influenza in a middle-aged woman in Spain [5] which came to attention almost by chance. The woman worked with pigs and suffered a mild self-limiting influenza-like illness for which few physicians would have taken a swab. However the general practitioner (GP) she consulted happened to be part of an active influenza surveillance scheme and a specimen was taken. This was passed on to the laboratory as a regular surveillance specimen and then recognised as being influenza $A(H 1 N 1)$ phylogenetically close to European H1N1 swine influenza viruses. Retrospective epidemiological investigations found no evidence of any further cases apart from the GP who had experienced similar symptoms but was not laboratory-confirmed [5].

Infection with swine influenza virus has been detected sporadically in humans since the 1950s and the human disease is usually clinically similar to disease caused by infections with human influenza viruses [4]. However, complications that include pneumonia and death have occasionally been reported in the literature in otherwise healthy adults without underlying disease [4]. On the whole, human infections with swine influenza virus, to date, have been different and much milder than those seen with avian influenza A (H5N1) [6] and more similar to infections with low pathogenic avian influenza viruses [7]. Single generation person to person transmission has been reported but appears to be rare and chains of transmission have not been observed in general [4]. Though it is not entirely clear what measures public health authorities should pursue when they discover such human infections, it seems reasonable to regard them as comparable to low pathogenic avian influenza and so deserving a similar approach [7].

There is one well-known exception to these generalisations. In 1976 an outbreak of swine influenza virus infections in humans was detected in recruits in a military camp in Fort Dix, New Jersey in the United States. The presumed link to pigs was never discovered but there was extensive human to human transmission, with over 200 infections resulting in 12 hospitalisations and one death [8]. This was human to human transmission of a novel influenza virus causing some significant human pathology, which today might be described as WHO Pandemic Phase 4 [9]. The unilateral decision was made by the national authorities to develop, produce and deploy a specific pandemic vaccine based on the new strain. However, the infections petered out and the vaccine was seemingly associated with occurrence of Guillain-Barré syndrome in a few recipients. Mass immunisation was terminated but the incident remains part of public health lore and has been reviewed extensively for its learning points $[10,11]$.

While the reported case in this issue and other sporadic cases pose little direct threat to humans, they expose important gaps in knowledge about these zoonotic influenzas. The true incidence of swine influenza in humans, for example, is unknown. Recent serologic studies in the United States, where there has been 
more attention to zoonotic swine influenza than in Europe, have consistently found higher seroprevalence rates and higher antibody titres against all swine influenza viruses in those working with pigs than in non-swine-exposed controls [12-15]. This, and the fact that the current infection was detected by accident, suggests that the few reported cases of symptomatic swine influenza in humans represent a larger number of undetected infections among those in contact with pigs. However, there are no comparable data available for Europe and the prevalence of swine influenza in humans cannot be estimated from such studies because of the possibility of partial serologic cross-reactivity in the haemagglutination-inhibition test between human and swine influenza virus strains of the same subtype. Epidemiologists have tried to adjust for this by statistical methods, but they agree "it is possible that the elevated titers compared by proportional odds modeling do not correlate with infection" [13]. This stresses the need for combined serological and virological surveillance in humans exposed to pigs to gain this information. There have been recent developments in surveillance of influenza in European swine populations, which is an essential starting point for the monitoring of swine flu in humans. A fruitful initiative has been the "European Surveillance Network for Influenza in Pigs (ESNIP)" (2000-2009) a European Commission funded project that ends next month.

Even if the magnitude of the risk of swine influenza virus infections to human health is unknown, it seems unlikely to be high. Two factors are probably restricting infection of humans, though both are neglected research areas. Firstly, the host range of influenza viruses is generally very restricted by a limited fitness of a given virus in a different host species. Studies on the infectivity of animal influenza viruses for cells of the human respiratory tract, and the molecular determinants involved, have however so far focused almost exclusively on avian influenza viruses [16-18]. Secondly, immunity to human $\mathrm{H} 1$ or $\mathrm{H} 3$ influenza viruses may partially protect against infection with swine viruses. But animal model experiments on this issue are lacking. This type of research is needed if we want to understand the risk of zoonotic influenza based on scientifically proven facts rather than hypotheses.

The unknown element is the risk of reassortment to produce a novel virus, even a pandemic strain either in the pig "mixing vessel" or in a human dually infected with a human and pig strain. In the United States there have recently appeared triple reassortant swine influenza viruses with avian, human and swine genes and these have then transmitted to humans $[19,20]$. Fortunately, these and similar swine influenza viruses [21] that can infect humans have not yet met any of the criteria to cause a human pandemic. The true risk can only become clear if epidemiological investigations are combined with experimental research. Some scientists have advocated offering seasonal influenza vaccination to persons working with pigs to reduce their risk of getting infected [15]. However, experience with workers with domestic poultry on this point is not encouraging [22]. In one audit attempt in Europe uptake of the vaccine was low and those offered immunisation were confused as to what they were being protected against. The possible efficacy of human influenza vaccines against swine influenza virus infection, on the other hand, also remains unknown.

Following the discovery in Spain it seems likely that more human infections will be detected and reported as has happened in North America. While such events will mean an improvement in surveillance rather than an increased risk, they highlight another area where closer human and animal surveillance is needed around a poorly understood zoonosis.

\section{Aknowledgements}

Angus Nicoll and ECDC would like to thank those that assisted with an earlier threat assessment about this case namely: Marion Koopmans, virologist, Rijksinstituut voor Volksgezondheid en Milieu (RIVM), the Netherlands; the World Health Organization (WHO) Regional Office for Europe: Roberta Andragetti and Caroline Brown; the United States Centers for Disease Control and Prevention contributors: Carolyn Bridges, Lyn Finelli and Tim Ureki; and, within ECDC: Rene Snacken, Vicente Lopez, Evelyn Depoortere, Annick Lenglet and Johan Giesecke.

\section{References}

1. Olsen CW, Brown I, Easterday BC, Van Reeth K. Swine influenza. In: Straw BE, Zimmerman JJ, D’Allaire S, Taylor DJ, editors. Diseases of Swine. 9th ed. Ames, Iowa: Iowa State University Press; 2006. p. 469-82.

2. Van Reeth K. Avian and swine influenza viruses: our current understanding of the zoonotic risk. Vet Res. 2007;38(2):243-60.

3. Van Reeth K, Brown IH, Dürrwald R, Foni E, Labarque G, Lenihan P, et al. Seroprevalence of $\mathrm{H} 1 \mathrm{~N} 1, \mathrm{H} 3 \mathrm{~N} 2$ and $\mathrm{H} 1 \mathrm{~N} 2$ influenza viruses in pigs in seven European countries in 2002-2003. Influenza and other respiratory viruses. 2008;2(3):99-105.

4. Myers KP, Olsen CW, Gray GC. Cases of swine influenza in humans: a review of the literature. Clin Infect Dis. 2007;44(8):1084-8.

5. Adiego Sancho B, Omeñaca Terés M, Martínez Cuenca S, Rodrigo Val P, Sánchez Villanueva P, Casas I, Pozo F, Pérez Breña P. Human case of swine influenza A (H1N1), Aragon, Spain, November 2008. Euro Surveill. 2009;14(7):pii=19120. Available from: http://www.eurosurveillance.org/ ViewArticle.aspx?ArticleId $=19120$

6. Writing Committee of the Second World Health Organization Consultation on Clinical Aspects of Human Infection with Avian Influenza A (H5N1) Virus, Abdel-Ghafar AN, Chotpitayasunondh T, Gao Z, Hayden FG, Nguyen DH, et al. Update on avian influenza A (H5N1) virus infection in humans. N Engl J Med. 2008 Jan 17;358(3):261-73.

7. Influenza team (ECDC). Low Pathogenicity Avian Influenzas and human health. Euro Surveill. 2007;12(22):pii=3209. Available from: http://www. eurosurveillance.org/ViewArticle. aspx? ArticleId $=3209$

8. Hodder RA, Gaydos JC, Allen RG, Top FH Jr, Nowosiwsky T, Russell PK. Swine influenza A at Fort Dix, New Jersey (January-February 1976). III. Extent of spread and duration of the outbreak. J Infect Dis. 1977;136 Suppl:S369-75.

9. World Health Organization. WHO global influenza preparedness plan. The role of WHO and recommendations for national measures before and during pandemics. Geneva: World Health Organization; 2005. Available from: http:// www.who.int/csr/resources/publications/influenza/WHO_CDS_CSR_GIP_2005_5. pdf

10. Neustadt RE, Fineberg HV. The swine flu affair: decision-making on a slippery disease. Honolulu: University Press of the Pacific; 2005.

11. Sencer DJ, Millar JD. Reflections on the 1976 swine flu vaccination program. Emerg Infect Dis. 2006;12(1):29-33.

12. Olsen CW, Brammer L, Easterday BC, Arden N, Belay E, Baker I, et al. Serologic evidence of $\mathrm{H} 1$ swine Influenza virus infection in swine farm residents and employees. Emerg Infect Dis. 2002;8(8):814-9.

13. Myers KP, Olsen CW, Setterquist SF, Capuano AW, Donham KJ, Thacker EL, et al. Are swine workers in the United States at increased risk of infection with zoonotic influenza virus? Clin Infect Dis. 2006;42(1):14-20.

14. Ramirez A, Capuano AW, Wellman DA, Lesher KA, Setterquist SF, Gray GC. Preventing zoonotic influenza virus infection. Emerg Infect Dis. 2006;12(6):9961000.

15. Gray GC, McCarthy T, Capuano AW, Setterquist SF, Olsen CW, Alavanja MC. Swine workers and swine influenza virus infections. Emerg Infect Dis. 2007;13(12):1871-8.

16. Matrosovich MN, Matrosovich TY, Gray T, Roberts NA, Klenk HD. Human and avian influenza viruses target different cell types in cultures of human airway epithelium. Proc Natl Acad Sci U S A. 2004;101(13):4620-4.

17. Wan H, Perez DR. Amino acid 226 in the hemagglutinin of H9N2 influenza viruses determines cell tropism and replication in human airway epithelial cells. J Virol. 2007;81(10):5181-91. 
18. Bateman AC, Busch MG, Karasin AI, Bovin N, Olsen CW. Amino acid 226 in the hemagglutinin of H4N6 influenza virus determines binding affinity for alpha 2,6-linked sialic acid and infectivity levels in primary swine and human respiratory epithelial cells. J Virol. 2008;82(16):8204-9.

19. Olsen CW, Karasin AI, Carman S, Li Y, Bastien N, Ojkic D, et al. Triple reassortant H3N2 influenza A viruses, Canada, 2005. Emerg Infect Dis. 2006;12(7):1132-5.

20. Newman AP, Reisdorf E, Beinemann J, Uyeki TM, Balish A, Shu B, et al. Human case of swine influenza A (H1N1) triple reassortant virus infection, Wisconsin. Emerg Infect Dis. 2008;14(9):1470-2.

21. Gregory V, Lim W, Cameron K, Bennett M, Marozin S, Klimov A, et al. Infection of a child in Hong Kong by an influenza A H3N2 virus closely related to viruses circulating in European pigs. J Gen Virol. 2001;82(Pt 6):1397-406.

22. Lyon AK, Davies T, Tahir M, Spraggett B. The English Seasonal Flu Immunization Programme for Poultry Workers 2007: a challenging task. J Public Health (Oxf) 2008 Sep;30(3):245-50.

This article was published on 19 February 2009.

Citation style for this article: Van Reeth K, Nicoll A. A human case of swine influenza virus infection in Europe - implications for human health and research . Euro Surveill. 2009;14(7):pii=19124. Available online: http://www.eurosurveillance.org/ViewArticle. aspx?ArticleId $=19124$ 